\title{
Overexpression of Cytosolic Ascorbate Peroxidase in Tomato Confers Tolerance to Chilling and Salt Stress
}

\author{
Yueju Wang1 \\ Department of Horticulture, Oregon State University, Corvallis, OR 97331-7304 \\ Michael Wisniewski² \\ USDA-ARS, 2217 Wiltshire Road, Kearneysville, WV 25430-9606 \\ Richard Meilan \\ Forestry \& Natural Resource Department, Purdue University, West Lafayette, IN 47907-2072 \\ Minggang Cui \\ Department of Horticulture, Oregon State University, Corvallis, OR 97331-7304
}

Robert Webb

USDA-ARS, 2217 Wiltshire Road, Kearneysville, WV 25430-9606

Leslie Fuchigami

Department of Horticulture, Oregon State University, Corvallis, OR 97331-7304

AdDitional INDEX WORDS. oxidative stress, transgenic plants, Lycopersicon esculentum

\begin{abstract}
Ascorbate peroxidase (APX) plays an important role in the metabolism of hydrogen peroxide in higher plants, affording them protection against oxidative stress. We studied the effect of overexpressing a cytosolic ascorbate peroxidase ( $c A P X)$ gene-derived from pea (Pisum sativum $\mathrm{L}_{\text {.) }}$-in transgenic tomato plants (Lycopersicon esculentum L.). Transformants were selected in vitro using kanamycin resistance and confirmed by polymerase chain reaction (PCR) and northern analyses. An APX native-gel assay indicated that, in the absence of stress, APX activity in transgenic plants was several times greater than that measured in wild-type (WT) plants. Several independently transformed lines were propagated and evaluated for resistance to chilling and salt stress. After placing seeds at $9{ }^{\circ} \mathrm{C}$ for 5 weeks, percent germination was greater for seeds obtained from transgenic lines (26\% to $37 \%$ ) compared to the WT (3\%). Plants from transgenic lines also had lower electrolyte leakage $(20 \%$ to $23 \%)$ than WT (44\%) after exposure to $4{ }^{\circ} \mathrm{C}$. Visual assessment of transgenic and WT lines exposed to salinity stress $(200$ or $250 \mathrm{~mm})$ confirmed that overexpression of APX minimized leaf damage. Moreover, APX activity was nearly 25- and 10-fold higher in the leaves of transgenic plants in response to chilling and salt stresses, respectively. Our results substantiate that increased levels of APX activity brought about by overexpression of a cytosolic APX gene may play an important role in ameliorating oxidative injury induced by chilling and salt stress.
\end{abstract}

As with many other environmental stresses, exposing plants to high salt levels or chilling results in oxidative damage from reactive oxygen species (ROS), such as superoxide $\left(\mathrm{O}_{2}-\right)$, hydrogen peroxide $\left(\mathrm{H}_{2} \mathrm{O}_{2}\right)$, and hydroxyl radicals $\left(\mathrm{OH}^{-}\right)$(Bruggemann et al., 1999; Prasad et al., 1994a, 1994b). ROS also may be generated in living cells during normal metabolism (Allen, 1995). ROS can damage plant membranes as well as DNA (Becana et al., 1998; Posmyk et al., 2001). Plants have developed both enzymatic, [e.g., superoxide dismutase (SOD, EC 1.15.1.1) and ascorbate peroxidase (APX) (EC 1.11.1.11)] and nonenzymatic (ascorbate or glutathione) systems to counter the effects of oxidative stress. SOD scavenges $\mathrm{O}_{2}-$ radicals and converts them to $\mathrm{H}_{2} \mathrm{O}_{2}$. APX catalyses the conversion of $\mathrm{H}_{2} \mathrm{O}_{2}$ to water, with ascorbate serving as the

Received for publication 16 June 2004. Accepted for publication 24 Aug. 2004. We are grateful to the Washington Tree Fruit Research Commission for their financial support. We also thank Dr. Lailiang Cheng (Cornell Univ., Ithaca, N.Y.) for lending technical advice and Dr. Steve Strauss (Oregon State Univ., Corvallis) for providing lab equipment.

${ }^{1}$ Current address: Plant Gene Expression Center, Plant \& Microbial Biology Dept., Univ. of California, Berkeley, CA 94720.

${ }^{2}$ To whom reprint requests should be addressed. (phone: 304-725-3451 x320; Fax: (304)728-2340; Email: mwisniew@afrs.ars.usda.gov) electron donor (Asada, 1992). In general, APX activities increase in plants exposed to various environmental stresses. This elevated activity is correlated with a rise in the levels of other antioxidant enzymes, such as catalase (CAT), SOD, and glutathione reductase (GR), which suggests that the components of ROS-scavenging systems are co-regulated (Allen, 1995; Pastori and Trippi, 1992; Sen Gupta et al., 1993; Shigeoka et al., 2002).

The injury manifested by low-temperature and salt stresses is believed to be lipid peroxidation caused by an increase in oxygen radical generation (Prasad et al., 1994a, 1994b; Shalata et al., 2001). After exposure to low temperatures, chilling-tolerant maize (Zea mays L.) exhibited higher SOD and APX activities compared with chilling-sensitive maize (Pinhero et al., 1997). In tomato, higher chilling tolerance prevents ROS formation and allows for better conversion of light to photochemical energy at suboptimal temperatures (Bruggemann et al., 1999).

The relationship between salt stress and antioxidant enzyme activity has been investigated in various plants (Dionisio-Sese and Tobita, 1998; Hernández et al., 1995, 1999, 2001; Shalata et al., 2001). Gueta-Dahan et al. (1997) have found that $c A P X$ and $\mathrm{Cu} / \mathrm{Zn}$-SOD in sweet orange (Citrus sinensis Osbeck) cells were similarly induced by salt and oxidative stresses. APX has been 
proposed as a key enzyme for imparting salt tolerance in citrus because its steady-state activity in salt-sensitive citrus callus is far below that observed in salt-tolerant citrus callus. Mittova et al. (2003) reported that the salt-stress-induced increase in cytosolic antioxidant enzyme activity in salt-tolerant tomato species also conferred cross-tolerance toward enhanced mitochondrial and peroxisomal ROS production. Shalata et al. (2001) found that, under salt stress, membrane lipid peroxidation gradually increased in salt-sensitive tomato roots. This response was accompanied by decreased activities of SOD, APX, and CAT. In contrast, the activity of these enzymes increased in salt-tolerant tomato roots, where the membrane lipid peroxidation levels remain unchanged.

Increased expression of antioxidant enzyme activity appears to be very effective in overcoming chilling and/or salt stresses in several crop species (Payton et al., 2001; Roxas et al., 2000; Tanaka et al., 1999; Van Breusegem et al., 1999) but has not been explored in horticultural plants. The objective of the present research was to evaluate changes in tolerance to chilling and salt stresses resulting from the overexpression of a pea cytosolic APX gene in tomato.

\section{Materials and Methods}

Production and propagation of transgenic Plants. Tomato plants (cv. Zhongshu No. 5) were transformed with a binary vector containing pea $c A P X$ cDNA (Mittler and Zilinskas, 1992) under the control of a dual cauliflower mosaic virus $35 \mathrm{~S}$ promoter and 35S terminator (Payton et al., 2001). The T-DNA contained the nopaline synthase (NOS) promoter fused to a neomycin phosphotransferase II gene (NPT II). This construct, pCGN1578, was transferred to the tomato cells via Agrobacterium [A.tumefaciens (Smith \& Towns.) Conn.] strain EHA105. Kanamycin-resistant plants were then regenerated using a technique described by Frary and Earle (1996), with modifications (Wang, 2003). Cotyledonary and hypocotyl explants were excised from 8- to 10 -d-old seedlings. These were incubated for 10 to $15 \mathrm{~min}$ in an Agrobacterium suspension diluted to an $\mathrm{OD}_{600}$ of 0.2 in a liquid Murashige-Skoog (MS) medium (Murashige and Skoog, 1962) that had been supplemented with $30 \mathrm{~g} \cdot \mathrm{L}^{-1}$ sucrose (MSO; pH 5.8). Afterward, they were blotted on sterile paper towels, plated on a co-cultivation medium $\left(\mathrm{MS}+40 \mathrm{mg} \cdot \mathrm{L}^{-1}\right.$ acetosyringone +1 $\mathrm{mg} \cdot \mathrm{L}^{-1}$ zeatin $+7 \mathrm{~g} \cdot \mathrm{L}^{-1}$ agar), and placed in the dark for 2 to $4 \mathrm{~d}$. The explants were then transferred to a selection medium (MS + $1 \mathrm{mg} \cdot \mathrm{L}^{-1}$ zeatin $+50 \mathrm{mg} \cdot \mathrm{L}^{-1} \mathrm{kanamycin}+400 \mathrm{mg} \cdot \mathrm{L}^{-1}$ cefotaxime $+7 \mathrm{~g} \cdot \mathrm{L}^{-1}$ agar), and the resultant shoots were placed on a rooting medium (MS + $50 \mathrm{mg} \cdot \mathrm{L}^{-1} \mathrm{kanamycin}+0.2 \mathrm{mg} \cdot \mathrm{L}^{-1} \mathrm{NAA}+400$ $\mathrm{mg} \cdot \mathrm{L}^{-1}$ cefotaxime $+7 \mathrm{~g} \cdot \mathrm{L}^{-1}$ agar). Culture was at $23{ }^{\circ} \mathrm{C} / 21{ }^{\circ} \mathrm{C}$ $\left( \pm 2{ }^{\circ} \mathrm{C}\right.$, day/night temperature) under cool white fluorescent and high-pressure sodium lights (100 to $\left.150 \mu \mathrm{mol} \cdot \mathrm{m}^{-2} \cdot \mathrm{s}^{-1}\right)$ with a 16-h photoperiod. Rooted cuttings from the regenerated plants were planted in a potting mix containing peat moss (Lakeland Peat Moss, Edmonton, Alberta, Canada), and grown under standard greenhouse conditions $\left[\approx 23{ }^{\circ} \mathrm{C} / 21{ }^{\circ} \mathrm{C}\left( \pm 2{ }^{\circ} \mathrm{C}\right.\right.$, day/night temperature)] with natural lighting supplemented with sodium vapor lights ( $1000 \mathrm{~W}$; Philips, Eindhoven, The Netherlands) from 0600 to $1000 \mathrm{HR}$. These original transgenic lines ( $\mathrm{T}_{0}$ generation) were self-pollinated to produce $T_{1}$ progeny. The $T_{1}$ plants were then self-pollinated to yield the $\mathrm{T}_{2}$ generation. All the transgenic plants were resistant to kanamycin.

AnALYSIS OF TRANSGENIC PLANTS. Putative transformants were screened for T-DNA insertion using PCR primers to amplify the
35S::APX fusions. Genomic DNA was isolated from wild-type (WT) and $A P X$-overexpressing plants $\left(\mathrm{T}_{1}\right)$, according to procedures described by Doyle and Doyle (1987). The sequences for the forward and reverse primers for 35S::APX included $5^{\prime}$-CACGTCTTCAAAGCAAGTGG-3' and 5'-GACTGCAGCTTCAGCAAATCC-3', respectively. About 20 ng DNA was used for PCR reaction, under the following conditions: $1 \mathrm{~min}$ at $94^{\circ} \mathrm{C}, 1 \mathrm{~min}$ at $60{ }^{\circ} \mathrm{C}$, and $2 \mathrm{~min}$ at $72{ }^{\circ} \mathrm{C}$ for 30 cycles. The amplified products were then separated electrophoretically on a $0.8 \%$ agarose gel, stained with ethidium bromide, and visualized and photographed under ultraviolet light. For the segregation analysis, $\approx 50$ seeds from WT and each independent line $\left(\mathrm{T}_{0}\right)$ were germinated on a solid MS medium containing kanamycin. After 7 to $10 \mathrm{~d}$, the cutting shoots were transferred to a selective rooting medium. Seedlings were scored for kanamycin resistance, and the ratio of resistant to sensitive plants was used to estimate the number of independent T-DNA insertions. All transformants were grown in potting mix to maturity in the greenhouse. These plants were then self-fertilized, and the resulting seed was collected from individual lines.

NoRTHERN BLOTS. Total RNA was prepared from the leaves of the WT and transgenic plants, using Tri-reagent as specified by the manufacturer (Molecular Research, Cincinnati). In order to ensure even loading, quantification of total RNA in all samples was determined with a spectrophotometer and by ethidium bromide staining of agorose gels. Briefly, $30-\mu$ g aliquots of total RNA were separated on a $1 \%(\mathrm{w} / \mathrm{v})$ denatured agarose gel and transferred to a nylon membrane. This procedure was followed by a Super Hyb Kit northern blot system procedure (Molecular Research). The membrane was probed with a ${ }^{32} \mathrm{P}$-labeled $A P X-\mathrm{PCR}$ fragment, and hybridizations were detected by a Phosphor-Imager SI (Molecular Dynamics, Sunnyvale, Calif.). The predicted size of the transcript is 0.75 kilobases $(\mathrm{kb})$.

EnZYMe ACTIVITY ASSAYs. For the APX activity-gel assays, about $100 \mathrm{mg}$ of the leaf tissue was ground to a fine powder in liquid nitrogen, and homogenized in $200 \mu \mathrm{L}$ of grinding buffer [100 $\mathrm{mm} \mathrm{NaPO}_{4}$ (pH 7.0), 5 mм ascorbate, 1 mм EDTA (pH 8.0), $10 \%$ glycerol, and $0.001 \%$ bromophenol blue]. The supernatant was collected and protein concentration was determined using a Protein Assay System (Bio-Rad, Hercules, Calif.). About $70 \mu \mathrm{g}$ of total protein was loaded on a non-denaturing, $10 \%$ polyacrylamide gel. It was then electrophoretically separated (via PAGE) for $5 \mathrm{~h}$ at $4{ }^{\circ} \mathrm{C}$ in a $1 \times$ Tris-glycine buffer ( $24 \mathrm{~mm}$ Tris and 192 mu glycine), followed by staining for APX activity, as described by Mittler and Zilinskas (1993).

For the SOD activity-gel assays, $\approx 100 \mathrm{mg}$ of the leaf tissue was finely ground in liquid nitrogen and homogenized in $200 \mu \mathrm{L}$ of grinding buffer [50 mm Tris ( $\mathrm{pH} 6.8$ ), 10\% glycerol, and $0.001 \%$ bromophenol blue]. About $70 \mu \mathrm{g}$ of soluble protein was then loaded on a nondenaturing, $10 \%$ polyacrylamide gel and electrophoretically separated for no more than $6 \mathrm{~h}$ at $4{ }^{\circ} \mathrm{C}$, as described by Van Camp et al. (1996). After staining, the gels were scanned with a Densitometer SI (Molecular Dynamics). ImageQuant 5.2 was used for image analysis (Molecular Dynamics).

Evaluation of tolerance to Chilling STRess. About 50 seeds each from WT and $\mathrm{T}_{1}$ generation were surface-sterilized and germinated at $9{ }^{\circ} \mathrm{C}$ in the dark on a solid MS medium. They were considered viable if the radicles were fully extended from the seed coats. After 5 and 8 weeks, percent seed germination was determined. Means $\pm \mathrm{SE}$ for four replicates were determined. Differences between means were evaluated by Duncan's multiple range test (NCSS-PASS software; NCSS, Williamsport, Pa.). 
Arcsine square root transformation was performed before data analysis.

Four-week-old transgenic $\mathrm{T}_{2}$ and the WT plants grown in plastic pots ( $15 \mathrm{~cm}$ diameter, $14.5 \mathrm{~cm}$ height) in the greenhouse were transferred to $4^{\circ} \mathrm{C}$ in the dark for chilling treatment. Two disks $(1.02 \mathrm{~cm}$ in diameter) from the fourth or fifth leaf from the apex were excised after $2,6,8$, or $10 \mathrm{~d}$ and ion leakage was determined with a conductivity meter (Markson Science, Del Mar, Calif.) according to the method described by Wisniewski et al. (1997). The percentage of electrolyte leakage due to the chilling treatment was calculated from these values. Means \pm SE for three replicates were determined. Differences between means were evaluated by Duncan's multiple range test. Arcsine square root transformation was performed before data analysis. For enzyme activity assay, leaf disks (under $4 \mathrm{~d}$ of the chilling stress) were taken from the WT and transgenic plants, frozen in liquid nitrogen, and stored at $-80{ }^{\circ} \mathrm{C}$.

Evaluation of tOlerance to SAlt stress. Cuttings from WT and transgenic $\mathrm{T}_{2}$ were grown in rooting medium for two weeks. Transgenic cuttings were screened on media containing $50 \mathrm{mg} \cdot \mathrm{L}^{-1}$ kanamycin. Healthy seedlings were transferred in 5.8 $\times 5.8 \times 8$-cm plastic pots filled with peat moss soil and watered with a commercial fertilizer $(9 \mathrm{~N}-4.4 \mathrm{P}-12.5 \mathrm{~K}$; Spectrum Brands, St. Louis) designed for tomatoes. Plants were grown under standard greenhouse conditions $\left[\approx 23{ }^{\circ} \mathrm{C} / 21{ }^{\circ} \mathrm{C}\left( \pm 2{ }^{\circ} \mathrm{C}\right.\right.$, day/night temperature)] with natural lighting supplemented with sodium vapor lights (1000W, Philips) from 0600 to $2200 \mathrm{~h}$. After 1 week, plants to be stressed were watered with fertilizer and either 200 or $250 \mathrm{~mm} \mathrm{NaCl}$ every $3 \mathrm{~d}$, and evaluated after 10, 20, and $30 \mathrm{~d}$. Nonstressed controls were watered only with fertilizer. Growth (from apex to soil) was measured $10 \mathrm{~d}$ after applying the salt stress. The extent of injury to leaves and whole seedlings was visually scored, with a scale of 0 to 5 used to estimate damage: $0=$ no damage symptoms; 1 = reduced growth and $<20 \%$ leaf area exhibiting injury; 2 = yellowing leaves, $21 \%$ to $40 \%$ of the leaf area injured; 3 = plants wilted, $41 \%$ to $60 \%$ leaf area injured; 4 = seriously damaged, the plant becoming flaccid and not remaining upright, $61 \%$ to $80 \%$ leaf area injured; $5=81 \%$ to $100 \%$ of the leaf area injured or else the plant had died. WT and the entire set of individual transgenic lines represented one block in the experimental design. The complete design was arranged as a randomized complete block with five blocks (replicates). Means \pm SE of five replicates were determined. The nonparametric Kruskal-Wallis test was used for analysis of ranks. The leaf discs from WT and transgenic plants under 10-d NaCl (200 mm) stress were then frozen in liquid nitrogen and stored at $-80{ }^{\circ} \mathrm{C}$ for further enzyme activity gel analyses.

\section{Results}

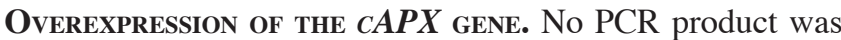
obtained from WT plants with $35 \mathrm{~S}$ promoter- and $c A P X$-specific primers, whereas an expected $0.9 \mathrm{~kb}$ fragment was amplified from DNAs from all transgenic lines (data not shown). As expected and verified using chi square analysis, the majority of lines exhibited a 3:1 segration for kanamycin resistance (and indirectly $c A P X$ ) in $\mathrm{T}_{1}$ plants (Table 1).

RNA northern blot analyses indicated that when total RNA from the WT and transgenic tomato leaves was hybridized with a full-length $c A P X$ probe, a signal $(750 \mathrm{~kb})$ was detected only in the transgenic lines (Fig. 1). Five of 14 lines exhibited relatively high levels of expression. Moreover, APX activity for two se-
Table 1. Chi square analysis of the expression of kanamycin resistance in seeds of the $T_{1}$ generation of transgenic tomato plants. Wild-type $=$ nontransformed plants; $\mathrm{ND}=$ not determined. $\mathrm{A} 1$ to $\mathrm{A} 30$ are transgenic seeds from independent lines; $\mathrm{df}=2$. Probability of 1 indicates a perfect fit to the expected segregation ratio whereas $P$ $\leq 0.05$ indicates a lack of fit. Kan+/Kan- refers to the number of plants exhibiting kanamycin resistance vs. those that do not exhibit kanamycin resistance.

\begin{tabular}{lccrc}
\hline Lines tested & Kan+/Kan- & Ratio & \multicolumn{1}{c}{$\chi^{2}$} & $P$ \\
\hline Wild-type & $0 / 89$ & --- & 267.00 & 0.00 \\
A1 & $36 / 0$ & ND & 12.00 & 0.00 \\
A3 & $39 / 14$ & $3: 1$ & 0.06 & 0.81 \\
A4 & $19 / 31$ & ND & 36.51 & 0.00 \\
A9 & $39 / 12$ & $3: 1$ & 0.06 & 0.81 \\
A13 & $36 / 12$ & $3: 1$ & 0.00 & 1.00 \\
A15 & $43 / 12$ & $3: 1$ & 0.30 & 0.59 \\
A16 & $44 / 13$ & $3: 1$ & 0.15 & 0.70 \\
A18 & $41 / 18$ & $3: 1$ & 0.95 & 0.33 \\
A25 & $1 / 39$ & untransformed & --- & --- \\
A30 & $27 / 9$ & $3: 1$ & 0.00 & 1.00 \\
\hline
\end{tabular}

WT A1 A9 A15 A16 A18 A3

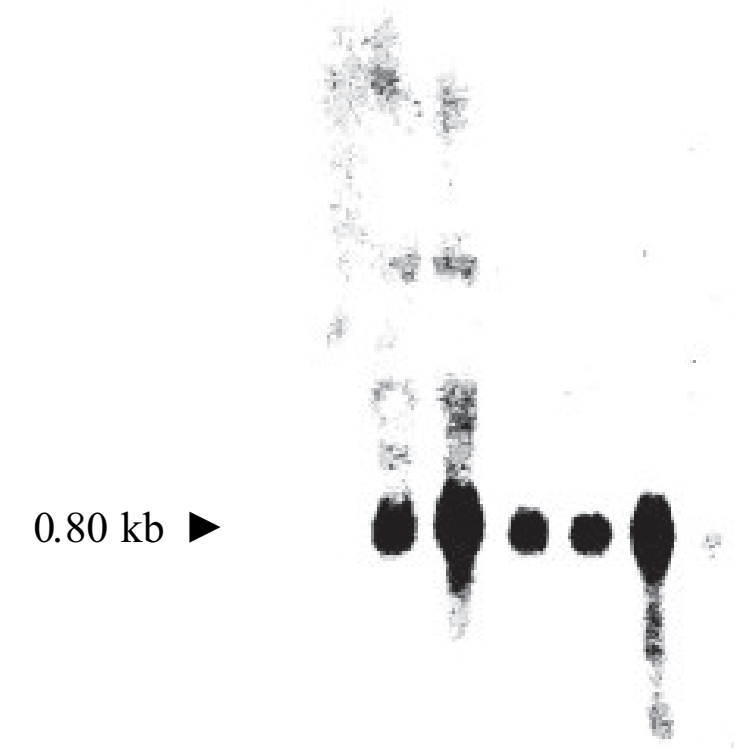

Fig. 1. Northern-blot analysis of RNA isolated from $T_{1}$ tomato plants. Thirty micrograms of total RNA was loaded in each lane. The blot was probed with a full-length, ${ }^{32} \mathrm{P}$-labeled $c A P X$ probe. WT, wild-type plants; A1-A30, independent transgenic lines. $c A P X$ refers to the pea ascorbate peroxidase gene used to transform tomato.

lected lines, A9 and A16, was 3- to 6-fold higher than from the WT plants (Fig. 2A).

Both SOD and APX are key enzymes in the oxygen-scavenging system. To determine if the expression of pea $c A P X$ in tomato plants affected SOD activity, we also examined levels of leaf SOD via a gel assay and found that activity in the APX+ lines was slightly elevated in the transgenic lines compared to WT 


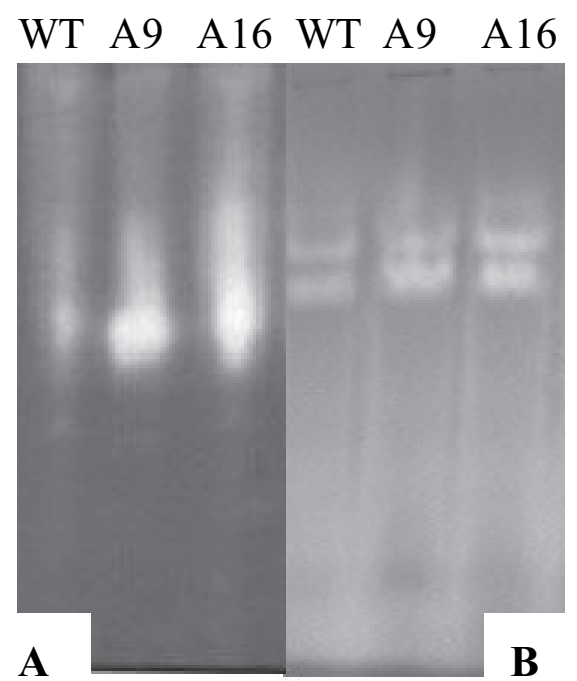

Fig. 2. Gel assays of ascorbate peroxidase (A) and superoxide dismutase (B) activities in wild-type and transgenic tomato plants under non-stressed condition. Seventy micrograms of protein was loaded in each lane of a nondenaturing polyacrylamide gel. WT refers to wild-type plants. A9 and A16 are independent transgenic lines overexpressing an ascorbate peroxidase gene.

plants based on a comparative estimation of the band intensity on the gels (Fig. 2B).

EFFects of CHILling. Hypocotyls and cotyledons developed normally from the $\mathrm{T}_{1}$ seeds, obtained from $\mathrm{T}_{0}$ plants, when they were germinated at $9{ }^{\circ} \mathrm{C}$. However, hypocotyl elongation from the WT seed was inhibited and no cotyledon expansion was apparent even after eight weeks. Germination was significantly greater among $\mathrm{T}_{1}$ seeds compared to WT seeds $(P<0.05)$. For example, after 5 weeks, $37 \%$ and $26 \%$ of the $\mathrm{T}_{1}$ seeds germinated in lines A9 and A16, respectively, compared to $3 \%$ of the WT seeds. After 8 weeks, the percent germination of transgenic seeds was $58 \%$ and $35 \%$ for lines A9 and A16, respectively, compared to $7 \%$ for WT seeds (Fig. 3). At normal growth temperatures (20 ${ }^{\circ} \mathrm{C}$ ), no differences in germination were observed between the WT and transformed lines (data not shown).

To study the effect of $c A P X$ expression on chilling tolerance, cellular injury was assessed by measuring solute leakage (Bowler et al., 1991). Significant differences $(P<0.05)$ were found between WT and $c A P X$ plants after $8 \mathrm{~d}$ of the low-temperature (4 $\left.{ }^{\circ} \mathrm{C}\right)$ treatment, with the transgenics showing lower leakage (23\% for A9 and 20\% for A16) than from the WT (44\%) (Fig. 4). After $10 \mathrm{~d}$, differences in electrolyte leakage persisted and actually increased between WT and transgenic lines, A9 and A16. Electrolyte leakage was $\approx 60 \%$ in the WT and $35 \%$ and $29 \%$ in transgenic lines A9 and A16, respectively (Fig. 4). APX and SOD enzyme activities were analyzed by gel assays after treatment for $4 \mathrm{~d}$ at 4 ${ }^{\circ} \mathrm{C}$ (Fig. 5). APX+ plants exhibited significant levels of activity compared to the WT plants where little to no APX activity could be detected (Fig. 5A). Little difference could be observed in SOD activity between the WT and transgenic lines (Fig. 5B) and SOD activity appeared to be less than the level of activity present in non-stressed controls (Fig. 2B).

EFFECTS OF SALT STRESS. Compared to the control plants, growth (measured as height) of both WT and transgenic plants was severely inhibited by $200 \mathrm{~mm} \mathrm{NaCl}$ (Fig. 6). However, transgenic plants were visibly less affected in their appearance by the salt solution, especially at $250 \mathrm{~mm}$ (Fig. 7). Wilting was obvious in leaves and stems of WT plants after $10 \mathrm{~d}$ of salt stress, and leaf injury, leaf and stem chlorosis, and, occasionally, necrosis and
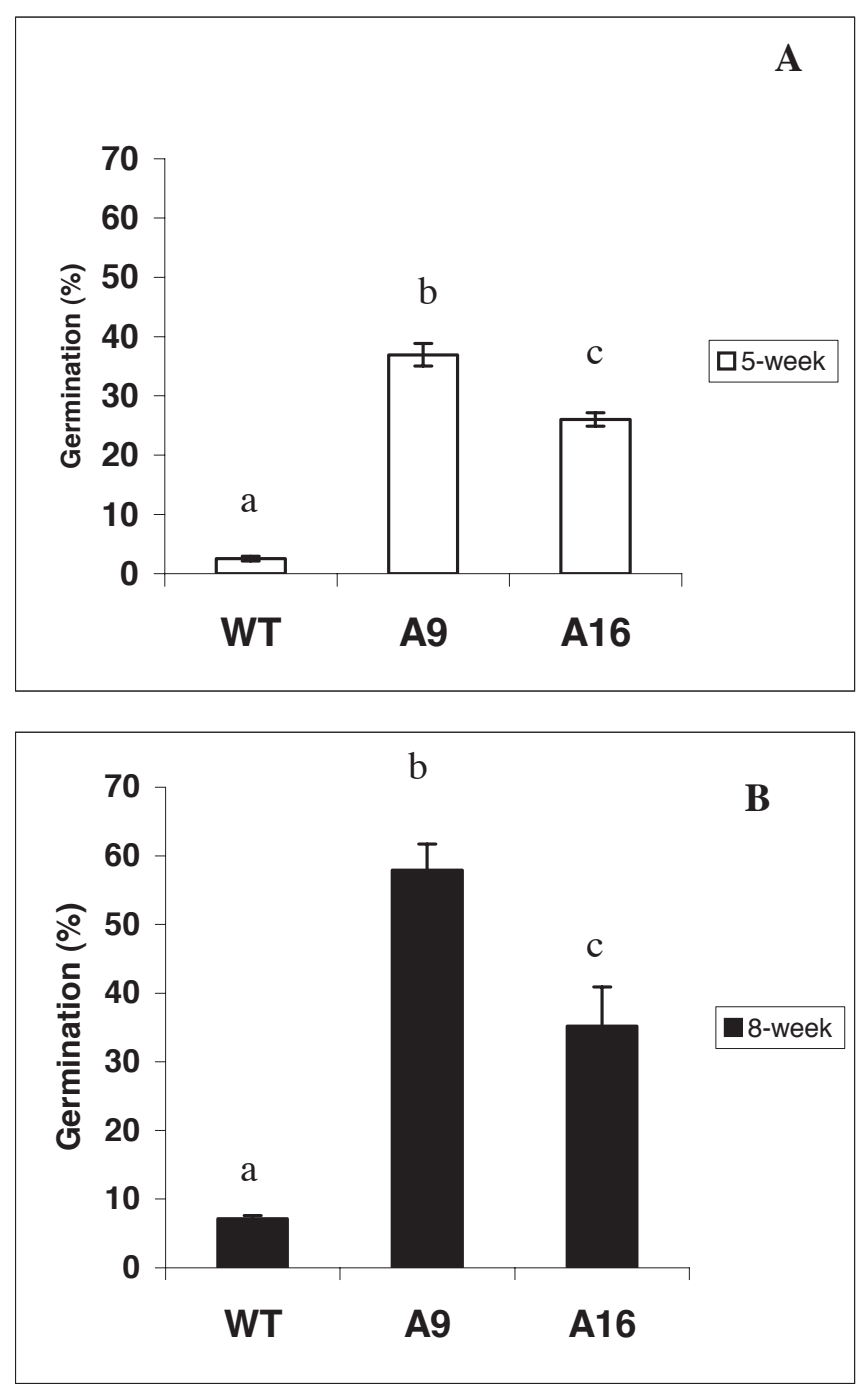

Fig. 3. Percent germination of seeds obtained from independent transgenic (A9 and A16) and wild-type (WT) lines of tomato plants after 5 (A) and 8 (B) weeks in the dark at $9{ }^{\circ} \mathrm{C}$. Values are means $\pm \mathrm{SE}(\mathrm{n}=4)$. Different letters indicate significant differences $(P<0.05)$ between lines at either 5 or 8 weeks by Duncan's multiple range test.

stem collapse had occurred. The average injury rating was 2.2 for WT plants receiving $200 \mathrm{~mm} \mathrm{NaCl}$ (Fig. 8A) and 4 for WT plants receiving $250 \mathrm{~mm} \mathrm{NaCl}$ (Fig. 8B). Plants from both the A9 and A16 lines (Fig. 8 A and B) began showing symptoms after $10 \mathrm{~d}$ of salt treatment but had significantly less injury $(P<$ 0.05 ) than WT plants. After $10 \mathrm{~d}$, the average injury rating of the transgenic lines was 1 at $200 \mathrm{~mm} \mathrm{NaCl}$ (Fig. 8A) and 2.2 at 250 mm NaCl (Fig. 8B). After 20 d, WT plants irrigated with $200 \mathrm{~mm}$ $\mathrm{NaCl}$ had an average injury rating of 3.6 and none of the plants that $250 \mathrm{~mm} \mathrm{NaCl}$ had survived (Fig. $8 \mathrm{~A}$ and B). Transgenic lines A9 and A16 were less affected $(P<0.05)$, with an average injury rating of 2.4 and 1.6, respectively, under the $200 \mathrm{~mm}$ treatment. Significant difference were observed in the level of injury of WT and transgenic lines treated with $250 \mathrm{~mm} \mathrm{NaCl}$ during the first $20 \mathrm{~d}$ (Fig. 8B). However, by $30 \mathrm{~d}$ both WT and transgenic plants exhibited a severe level of injury.

APX activity was also induced by salt stress, with levels in the transgenic leaves being considerably higher than in WT plants after $10 \mathrm{~d}$ of treatment with $200 \mathrm{~mm} \mathrm{NaCl}$ (Fig. 9A). In contrast, 


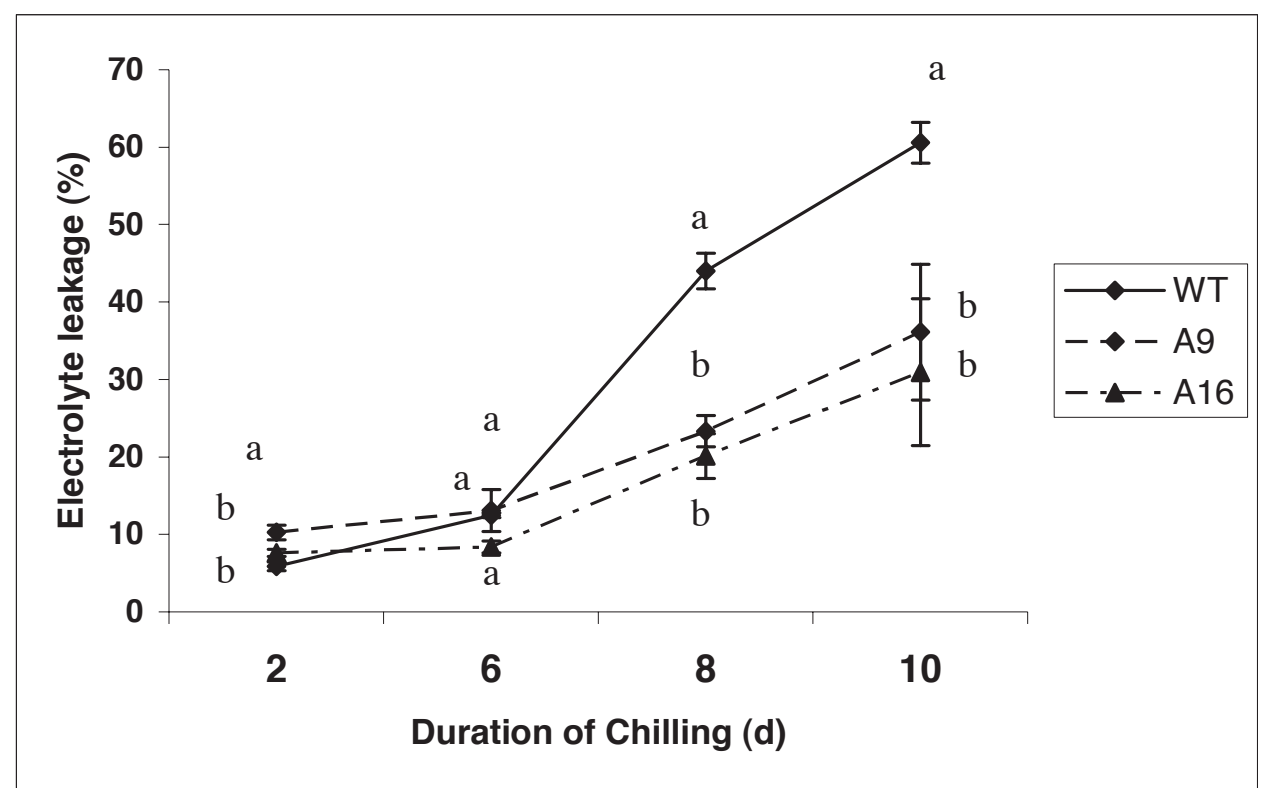

Fig. 4. Percent electrolyte leakage from wild-type (WT) and transgenic tomato plants (A9 and A16) following chilling stress $\left(4^{\circ} \mathrm{C}\right)$ for $2,6,8$, and $10 \mathrm{~d}$. Data represents mean $\pm \mathrm{SE}(\mathrm{n}=3)$. Different letters indicate significant differences $(P<0.05)$ between means within each sampling time (Duncan's multiple range test). previous reports and demonstrate that ectopic expression of the pea $c A P X$ gene in tomato confers increased resistance to oxidative damage caused by exposure to chilling temperatures or high salt levels.

Seed germination is characterized by the rapid generation of superoxide and $\mathrm{H}_{2} \mathrm{O}_{2}$ following imbibition (Gidrol et al., 1994; Puntarulo, 1994). Under chilling conditions, the activities of antioxidant enzymes, including SOD, peroxidase, and glutathione reductase, significantly increase to limit the damage caused by such oxidative stress (Posmyk etal., 2001). We demonstrated that, at a low temperature $\left(9{ }^{\circ} \mathrm{C}\right)$, germination rates were higher for seeds from transgenic tomato plants that overexpressed $c A P X$ compared with WT seeds (Fig. 3). These results suggest that the enhanced level of APX may detoxify $\mathrm{H}_{2} \mathrm{O}_{2}$ to $\mathrm{H}_{2} \mathrm{O}$, thereby alleviating oxidative stress and increasing germination. In addition,

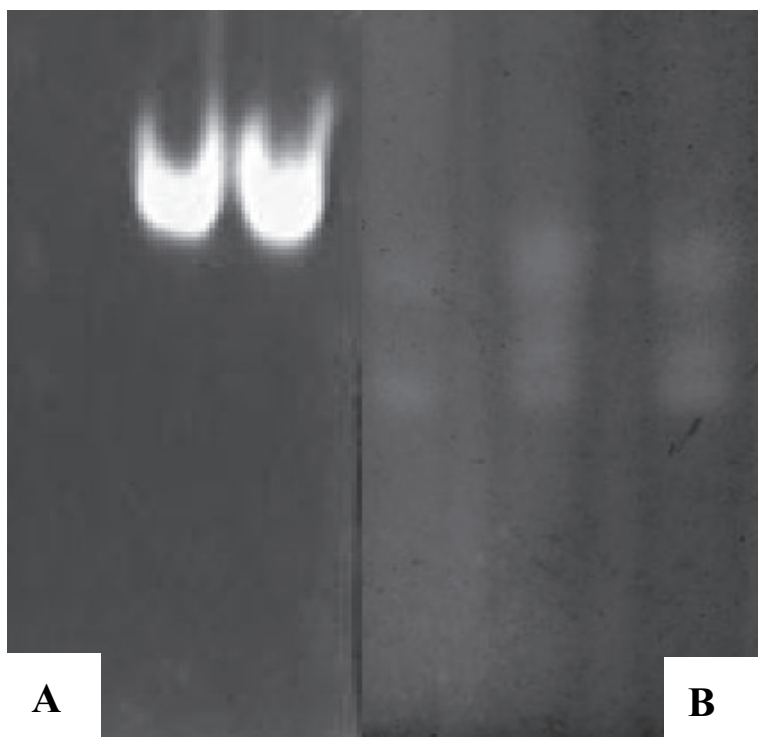

Fig. 5. Ascorbate peroxsidase (A) and superoxide dismutase (B) enzyme activities in wild-type (WT) and transgenic plants (A9 and A16) after chilling for $4 \mathrm{~d}$ at 4 ${ }^{\circ} \mathrm{C}$. Seventy micrograms of protein was loaded in each lane of the nondenaturing polyacrylamide gel.

salt stress decreased SOD activity in both the transgenic and the WT plants compared to unstressed plants (Fig. 2B and 9B, respectively).

\section{Discussion}

Overexpression of antioxidant genes in plants has been previously shown to provide enhanced tolerance to oxidative stress in several crop species (Allen, 1995; Gueta-Dahan et al., 1997; Payton et al., 2001; Roxas et al., 2000). Our results support the leakage of electrolytes was lower in transgenic plants in response to chilling at $4{ }^{\circ} \mathrm{C}$ (Fig. 4) suggesting less disruption to the plasma membrane in $c A P X$ plants. At $4^{\circ} \mathrm{C}$, APX activity in the transgenic tomatoes was 25-fold higher than in the WT plants (Fig. 5A). Therefore, we suspect that this elevated activity is a requirement for higher rates of $\mathrm{H}_{2} \mathrm{O}_{2}$ detoxification at lower temperatures (Pastori et al., 2000), thereby protecting membrane integrity.

Mittova et al. (2002) have demonstrated that salt stress induces up-regulation of an efficient chloroplast antioxidant system in salt-tolerant wild tomatoes but not in the cultivated species. This response by the former is characterized by increased activities of the ROS-scavenging enzymes SOD, APX, and GR. In our study as well, the level of APX was significantly higher in the transgenic $c A P X$ tomatoes than in the WT plants watered with $200 \mathrm{~mm} \mathrm{NaCl}$ (Fig. 9A). This overexpression apparently enabled the transformed plants to better tolerate the salt stress. Since APX is involved in detoxifying ROS, the increased resistance to salt stress was most likely due to an increased ability to recover from injury rather than a direct resistance to the negative effects of exposure to high concentrations of an ionic solution such as sodium chloride. A similar hypothesis regarding the impact of the overexpression of a superoxide dismutase (SOD) gene in alfalfa (Medicago sativa L.) was stated by McKersie et al. (1993) and Bridger et al. (1994). In this work, constitutive expression of an SOD gene resulted in increased cold tolerance. Since APX works in conjuction with SOD and other antioxidant enzymes to detoxify ROS, it is possible that the overexpression of the cytosolic APX may have also induced uupregulation of native APX, SOD, and antioxidant genes. Increased resistance of tomato to oxidative stress has also been observed when just an SOD gene alone has been overexpressed in transgenic plants (Wang, 2003). Co-regulation of antioxidant enzymes has been previously reported (Allen, 1995; Sen Gupta et al., 1993) and such feed back or cross-talk within a pathway, such as the antioxidant system, is not uncommon.

In both chilling- and salt-stress tests, APX activity was greater in transgenic plants, compared to WT plants, effectively amelio- 


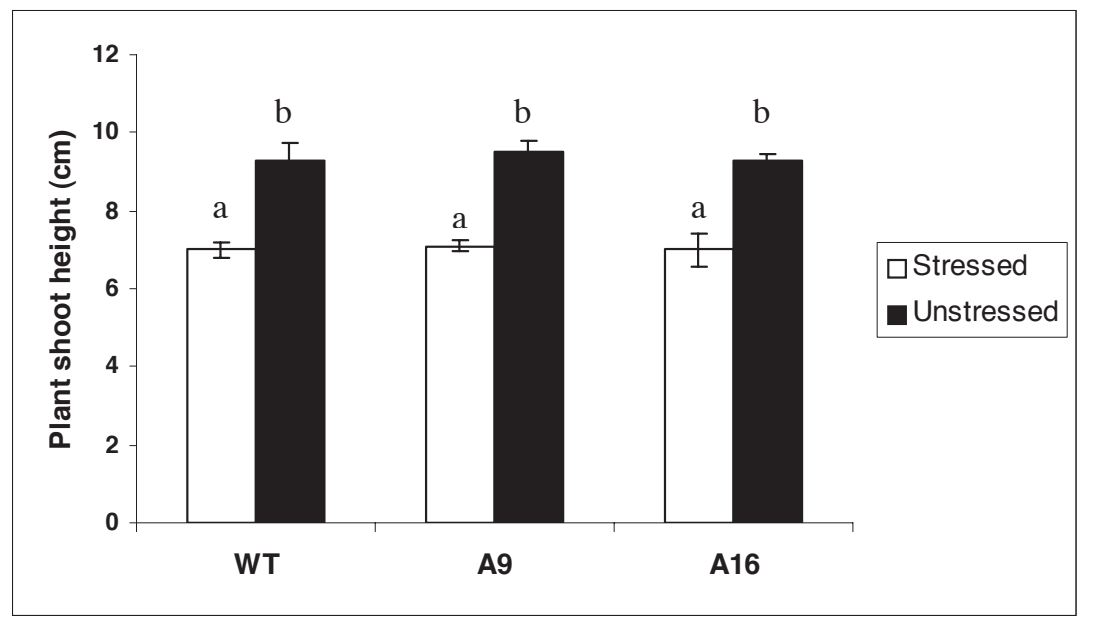

Fig. 6. Effect of salt stress on growth (height) of seedlings of wild-type (WT) and transgenic tomato plants (A9 and A16). Shoot height (measured from the soil line to terminal meristem) was measured after 10 d. Unstressed, 0 $\mathrm{mm} \mathrm{NaCl}$; Stressed, $200 \mathrm{~mm}, \mathrm{NaCl}$. Data are means $\pm \mathrm{SE}(\mathrm{n}=3)$. Different letters indicate significant differences $(P<0.05)$ between means $(t$ test $)$.
A

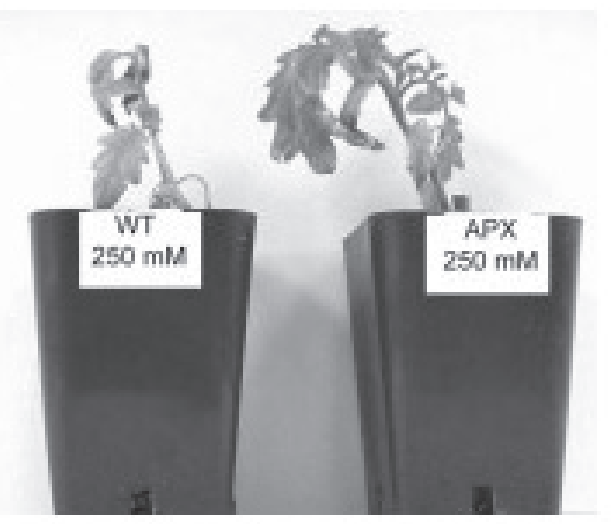

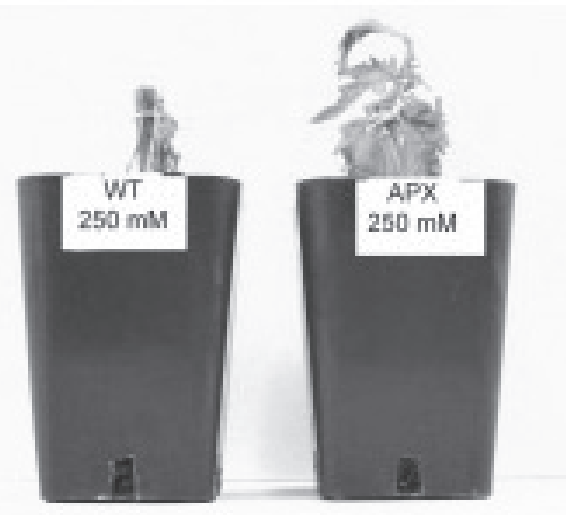

B
Fig. 7. Effect of salt stress on wild-type (WT) and transgenic tomato plants overexpressing a cytosolic ascorbate peroxidase gene from pea. Plants were watered with $250 \mathrm{~mm} \mathrm{NaCl}$ for $10 \mathrm{~d}(\mathbf{A})$ and $18 \mathrm{~d}$ (B), respectively. WT died after $18 \mathrm{~d}$ treatment. Transgenic leaves had less curling and wilting, an indication of greater tolerance. dismutase can reduce cellular damage mediated by oxygen radical in transgenic plants. EMBO J. 10(7):723-1732.

Bridger, G.M., W. Yang, D.E. Falk, and B.D. McKersie. 1994. Cold acclimation increases tolerance of activated oxygen species in winter cereals. J. Plant Physiol. 144:235-240.

Bruggemann, W., V. Beyel, M. Brodka, H. Poth, M. Weil, and J. Stockhaus. 1999. Antioxidants and antioxidative enzymes in wild-type and transgenic Lycopersicon genotypes of different chilling tolerance. Plant Sci. 140:145-154.

Dionisio-Sese, M.L. and S. Tobita. 1998. Antioxidant responses of rice seedlings to salinity stress. Plant Sci. 135(1):1-9.

Doyle, J.J. and J.I. Doyle. 1987. Isolation of plantDNA from fresh tissue. Phytochem. Bul. Bot. Soc. Amer. 19:11-15.

Frary, A. and D.E. Earle. 1996. An examination of factors affecting the efficiency of Agrobacterium-mediated transformation of tomato. Plant Cell Rpts. 16:235-240.

Gidrol, X., W.-S. Lin, N. Degousee, S.F. Yip, and A. Kush. 1994. Accumulation of reactive oxygen species and oxidation of cytokinin in germinating soybean seeds. Eur. J. Biochem. 224(1):21-28.

Gueta-Dahan, Y.,Z. Yaniv, B.A.Zilinskas, and G. Ben-Hayyim. 1997. Salt and oxidative Stress: Similar and specific responses and their relation to salt tolerance in citrus. Planta 203:460-469.

Hernández, J.A., E. Olmos, F.J. Corpas, F. Sevilla, and L.A. del Río. 1995. Saltinduced oxidative stress in chloroplasts of pea plants. Plant Sci. 105:151-167.

Hernández, J.A., A. Campillo, A. Jimenez, J.J. Slarcon, and F. Sevilla. 1999. Response of antioxidant systems and leaf water relations to $\mathrm{NaCl}$ stress in pea plants. New Phytol. 141:241-251.

rating the effect of chilling and salt stress. This research demonstrates that overexpression of a single gene can lead to enhanced resistance to environmental stress and could be a useful approach to improving stress resistance in existing cultivars of tomato once transgenic technologies are more widely accepted by the general public and the costs associated with regulatory approval become less prohibitive. Our data, and the cited literature, also suggest, however, that antioxidant enzymes, such as APX and SOD, may serve as good physiological or molecular markers in marker-assisted breeding programs aimed at increasing resistance to environmental stress.

\section{Literature Cited}

Allen, R.D. 1995. Dissection of oxidative stress tolerance using transgenic plants. Plant Physiol. 107:1049-1054.

Asada, K. 1992. Ascorbate peroxidase-A hydrogen peroxide-scavenging enzyme in plants. Physiol. Plant. 85:235-241.

Becana, M., J.F. Moran, and I. Iturbe-Ormaetxe. 1998. Iron dependent oxygen free radical generation in plants subjected to environmental stress: Toxicity and antioxidant protection. Plant Soil 201:137-147.

Bowler, C., L. Slooten, S. Vandenbranden, R.D. Rycke, J. Botterman, S. Sybesma, M.Van Montagu, and D. Inzé. 1991. Manganese superoxide
Hernández, J.A., M.A. Ferrer, A. Jiménez, A. Ros Barceló, and F. Sevilla. 2001. Antioxidant systems and $\mathrm{O}_{2}-/ \mathrm{H}_{2} \mathrm{O}_{2}$ production in the apoplast of pea leaves. Its relation with salt-induced necrotic lesions in minor veins. Plant Physiol. 127:817-831.

McKersie, B.D., Y. Chen, M. de Beus, S.R. Bowley, C. Bowler, D. Inze, K.D. D'Halluin, and J. Botterman. 1993. Superoxide dismutase enhances tolerance of freezing stress in transgenic alfalfa. Plant Physiol. 103:1155-1163.

Mittler, R. and B.A. Zilinskas. 1992. Molecular cloning and charaterization of a gene encoding pea cytosolic ascorbate peroxidase. J. Biol. Chem. 267(30):21802-21807.

Mittler, R. and B.A. Zilinskas. 1993. Detection of ascorbate peroxidase activity in native gels by inhibition of the ascorbate-dependent reduction of nitroblue tetrazolium. Anal. Biochem. 212:540-546.

Mittova V., M. Tal, M. Volokita, and M. Guy. 2002. Salt stress induces up-regulation of an efficient chloroplast antioxidant system in the salt-tolerant wild tomato species Lycopersicon pennellii but not in the cultivated species. Physiol. Plant. 115:393-400.

Mittova, V., M. Tal, M. Volokita, and M. Guy. 2003. Up-regulation of the leaf mitochondrial and peroxisomal antioxidative systems in response to salt-induced oxidative stress in the wild salt-tolerant tomato species Lycopersicon pennellii. Plant Cell Environ. 26:845-856.

Murashige, T. and F. Skoog. 1962. Arevised medium for rapid growth and bioassay with tobacco tissue cultures. Plant Physiol. 15:473-479. 

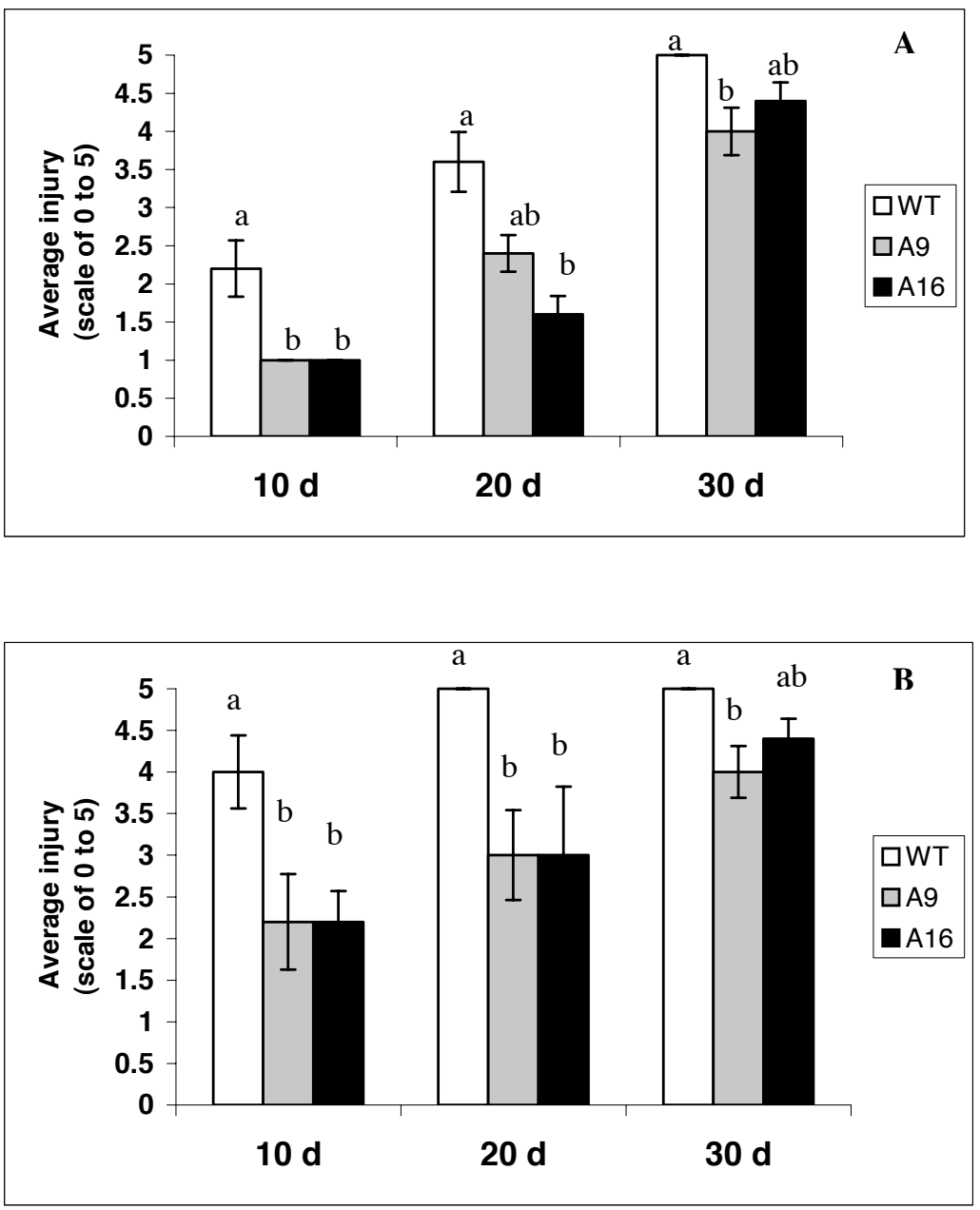

Fig. 8. Effect of $200 \mathrm{~mm}$ (A) or $250 \mathrm{~mm}$ (B) $\mathrm{NaCl}$ treatments on injury to wild-type (WT) and transgenic (A9 and A16) tomato plants after 10, 20, and $30 \mathrm{~d}$. No visible injury $=0$; slow growth, and $<20 \%$ visible injury $=1$; yellowing leaves and $21 \%$ to $40 \%$ of leaf area with visible injury $=2$; wilted plants and $41 \%$ to $60 \%$ visible injury $=3$; seriously damaged plant unable to remain upright with $61 \%$ to $80 \%$ visible injury $=4$; dead plant or $>80 \%$ visible injury $=5$. Values are means $\pm \mathrm{SE}(\mathrm{n}=$ $5)$. Different letters indicate significant differences $(P<0.05)$ between means within a sampling time (Kruskal-Wallis test).

\section{WT A9 A16 WT A9 A16}

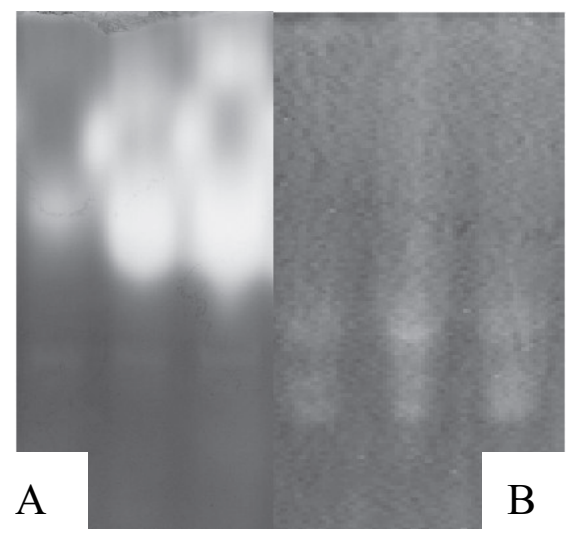

Fig. 9. Ascorbate peroxidase (A) and superoxide dismutase (B) enzyme activities in wild-type (WT) and transgenic (A9 and A16) tomato plants treated with 200 $\mathrm{mm} \mathrm{NaCl}$ for $10 \mathrm{~d}$. Seventy micrograms of protein was loaded in each lane of a nondenaturing polyacrylamide gel.
Pastori, G.M. and V.S. Trippi. 1992. Oxidative stress induces high rate of glutathione reductase synthesis in a drought-resistant maize strain. Plant Cell Physiol. 33:957-961.

Pastori, G., C.H. Foyer, and P. Mullineaux. 2000. Low temperature-induced changes in the distribution of $\mathrm{H}_{2} \mathrm{O}_{2}$ and antioxidants between the bundle sheath and mesophyll cells of maize leaves. J. Expt. Bot. 51:107-113.

Payton, P., R. Webb, D. Kornyeyev, R. Allen, and S.A. Holaday. 2001. Protecting cotton photosynthesis during moderate chilling at high light intensity by increasing chloroplastic antioxidant enzyme activity. J. Expt. Bot. 52(365):2345-2354.

Pinhero, R.G., M.V. Rao, G. Paliyath, D.P. Murr, and R.A. Fletcher. 1997. Changes in activities of antioxidant enzymes and their relationship to genetic and paclobutrazol-induced chilling tolerance of maize seedling. Plant Physiol. 114:695-704.

Posmyk, M.M., F. Corbineau, D. Vinel, C. Bailly, and D. Côme. 2001. Osmoconditioning reduces physiological and biochemical damage induced by chilling in soybean seeds. Physiol. Plant. 111(4):473-482.

Prasad, T.K., M.D. Anderson, B.A. Martin, and C.R. Stewart. 1994a. Evidence for chilling-induced oxidative stress in maize seedlings and a regulatory role for hydrogen peroxide. Plant Cell 6:65-74.

Prasad, T.K., M.D. Anderson, and C.R. Stewart. 1994b. Acclimation, hydrogen peroxide and abscisic acid protect mitochondria against irreversible chilling injury in maize seedling. Plant Physiol. 105:619-627.

Puntarulo, S. 1994. Effects of oxidative stress during imbibition of soybean embryonic axes. Proc. Royal. Soc. Edinburgh 102B:279-286.

Roxas, V.P., S.A. Lodhi, D.K. Garrett, J.R. Mahan, and R.D. Allen. 2000. Stress tolerance in transgenic tobacco seedlings that overexpress glutathione Stransferase/glutathione peroxidase. Plant Cell Physiol. 41(11):1229-1234.

Sen Gupta, A., R.P. Webb, A.S. Holaday, and R.D. Allen. 1993. Overexpression of superoxide dismutase protects plants from oxidative stress. Plant Physiol. 103:1067-1073.

Shalata, A., V. Mittova, M. Volokita, M. Guy, and M. Tal. 2001. Response of the cultivated tomato and its wild salt-tolerant relative Lycopersicon pennellii to salt-dependent oxidative stress: The root antioxidant system. Physiol. Plant. 112:487-494.

Shigeoka, S., T. Ishikawa, M. Tamoi, Y. Miyagawa, T. Takeda, Y. Yabuta, and K. Yoshimura. 2002. Regulation and function of ascorbate peroxidase isoenzyme. J. Expt. Bot. 53(372):1305-1319.

Tanaka, K., T. Hibino, Y. Hayashi, A. Tanaka, S. Kishitani, T. Takabe, S. Yokota, and T. Takabe. 1999. Salt tolerance of transgenic rice overexpression yeast mitochondrial Mn-SOD in chloroplasts. Plant Sci. 148:131-138.

Van Breusegem, F., L. Slooten, J. Stassart, J. Botterman, T. Moens, M.Van Montagu, and D. Inzé. 1999. Effects of overproduction of tobacco MnSOD in maize chloroplasts on foliar tolerance to cold and oxidative stress. J. Expt. Bot. 50(330):71-78.

Van Camp, W., K. Capiau, M. Van Montagu, D. Inzé, and L. Slooten. 1996. Enhancement of oxidative stress tolerance in transgenic tobacco plants overproducing Fe-superoxide dismutase in chloroplasts. Plant Physiol. 112:1703-1714.

Wang, Y. 2003. Overexpression of antioxidant genes in transgenic tomatoes tolerant against multiple stresses. PhD Diss. Oregon State Univ., Corvallis.

Wisniewski, M., J. Sauter, L. Fuchigami, and V. Stepien. 1997. Effects of near-lethal heat stress on bud break, heat-shock proteins and ubiquitin in dormant poplar (Populus nigra charkowiensis $\times$ P. nigra incrassata). Tree Physiol. 17(7):483-450. 